\title{
A Network Centered on Ventral Premotor Cortex Exerts Both Facilitatory and Inhibitory Control over Primary Motor Cortex during Action Reprogramming
}

\author{
Ethan R. Buch, ${ }^{1,2,3}$ Rogier B. Mars, ${ }^{1,2}$ Erie D. Boorman, ${ }^{1,2}$ and Matthew F. S. Rushworth ${ }^{1,2}$ \\ ${ }^{1}$ Department of Experimental Psychology, University of Oxford, Oxford OX1 3UD, United Kingdom, ${ }^{2}$ Centre for Functional Magnetic Resonance Imaging of \\ the Brain, University of Oxford, John Radcliffe Hospital, Oxford OX3 9DU, United Kingdom, and ${ }^{3}$ Human Cortical Physiology and Stroke \\ Neurorehabilitation Section, Medical Neurology Branch, National Institute of Neurological Disorders and Stroke, Bethesda, Maryland 20892-1430
}

\begin{abstract}
Ventral premotor cortex (PMv) is widely accepted to exert an important influence over primary motor cortex (M1) when hand movements are made. Although study of these interactions has typically focused on their excitatory nature, given its strong connections with both ventral and opercular frontal regions, one feature of the influence of PMv over M1 may be inhibitory. Paired-pulse transcranial magnetic stimulation (ppTMS) was used to examine functional interactions between human PMv and M1 during the selection and reprogramming of a naturalistic goal-directed action. One of two cylinders was illuminated on each trial. It was then grasped and picked up. On some trials, however, subjects had to reprogram the action as the illuminated cylinder was switched off and the other illuminated simultaneously with reach initiation. At a neurophysiological level, the PMv paired-pulse effect (PPE) on M1 corticospinal activity was facilitatory after the initial target presentation and during movement initiation. When reprogramming was required, however, the PPE became strongly inhibitory. This context-dependent change from facilitation to inhibition occurred within $75 \mathrm{~ms}$ of the change of target. Behaviorally, PMv-M1 ppTMS disrupted reprogramming. Diffusion-weighted magnetic resonance image scans were taken of each subject. Intersubject differences in the facilitation-inhibition contrast of PMv-M1 interactions were correlated with fractional anisotropy of white-matter in ventral prefrontal, premotor, and intraparietal brain areas. These results suggest that a network of brain areas centered on PMv inhibits M1 corticospinal activity associated with undesired movements when action plans change.
\end{abstract}

\section{Introduction}

Ventral premotor cortex (PMv) is a likely source of influence over primary motor cortex (M1) during grasping. In monkeys, M1 receives dense input from PMv (Godschalk et al., 1984; Dum and Strick, 2005), and stimulation of PMv modulates M1-corticospinal excitability under anesthesia (Shimazu et al., 2004) and during reaching and grasping (Prabhu et al., 2009). Additionally, PMv is also a likely source of inhibitory influence over M1. Among premotor areas, $\mathrm{PMv}$ is the recipient of the densest projections from lateral prefrontal cortex, especially from opercular and ventral prefrontal cortex (PFv) (Dum and Strick, 2005).

PFv plays an important attentional role and determines what stimuli are relevant for behavior (Everling et al., 2002; Rushworth et al., 2005). When an action-relevant stimulus changes, PMv may be well placed to reprogram the action, making it more appropriate for the new context. Moreover, a growing body of work implicates inferior frontal cortex in the inhibition of action. Although discussion of these data has primarily focused on more

Received 0ct. 1, 2009; accepted Nov. 5, 2009.

This work was supported by the Medical Research Council UK (M.F.S.R.), the award of a Marie Curie IntraEuropean Fellowship within the sixth European Community Framework Programme (R.B.M.), and the intramural program of the National Institute of Neurological Disorders and Stroke.

Correspondence should be addressed to Ethan R. Buch, Department of Experimental Psychology, University of Oxford, South Parks Road, 0xford 0X1 3UD, UK. E-mail: ethan.buch@psy.ox.ac.uk.

DOI:10.1523/JNEUROSCI.4882-09.2010

Copyright $\odot 2010$ the authors $\quad 0270-6474 / 10 / 301395-07 \$ 15.00 / 0$ rostral frontal cortex, PMv also falls within the critical region reported (Aron et al., 2004; Forstmann et al., 2008). Finally, PMv connects and interacts with intraparietal sulcal (IPS) regions (Verhagen et al., 2008, Rushworth et al., 2006) involved in the redirection and change of actions (Desmurget et al., 1999; Rushworth et al., 2001; Glover et al., 2005; Tunik et al., 2005).

Functional interactions between premotor cortex and M1 during action selection can be measured at subsecond timescales in humans with paired-pulse transcranial magnetic stimulation (ppTMS) (Koch et al., 2006; Boorman et al., 2007). In a baseline condition, a single TMS "test" pulse is applied over M1 (spTMS) and a motorevoked potential (MEP) is measured. On some trials, a preceding "conditioning" pulse is applied milliseconds earlier over another brain area, and its impact on the size of the MEP elicited by the same "test" pulse is measured. Conditioning pulses over dorsal premotor cortex (PMd) or presupplementary motor area (pre-SMA) cause a facilitatory paired-pulse effect (PPE) 75-125 ms after cues instructing subjects to make movements (Koch et al., 2006; O'Shea et al., 2007; Mars et al., 2009). Although M1 facilitation by several premotor regions has been reported in ppTMS action selection experiments, reports of an inhibitory influence have not been prominent. Inhibitory control of $\mathrm{M} 1$ by premotor cortex during action selection may be contextually gated, however, and thus more evident when the selected action must be changed and reprogrammed.

The aim of the current experiment was to examine PMv-M1 interactions during reprogramming of naturalistic grasping ac- 
tions at three levels: (1) neurophysiological interactions, (2) behavior, and (3) related anatomical connections. The focus was on whether task-mandated reprogramming of grasping behavior is associated with M1-corticospinal inhibition at a neurophysiological level, and whether intersubject variance in this inhibition can be explained by differences in the connectivity between PMv and remote brain regions. To assess these relationships, the impact of PMv-M1 ppTMS on grasping kinematics was measured, and diffusion-weighted magnetic resonance image (DW-MRI) brain scans were performed.

\section{Materials and Methods}

Subjects. Fourteen healthy, right-handed adults (9 females) participated in the experiment. All subjects received T1-weighted structural MRI scans, with 13 also receiving DW-MRI scans. Six healthy, right-handed adults (3 females) participated in a control experiment. Written informed consent was obtained for all subjects before participation in accordance with a project approval from the National Research Ethics Service (Oxford RECC, No. 05-Q1606-96).

Behavioral task. Subjects were seated in a darkened room, and performed reaching and grasping movements with their right hand, cued by the illumination of one of two concentrically arranged cylinders (15 and $65 \mathrm{~mm}$ diameter) placed in front of them at a distance of $30 \mathrm{~cm}$ (starting position to origin) (Glover et al., 2005). Reaction and movement times, as well as kinematic data for the thumb, index finger and wrist were recorded. Each trial was initiated once a touch-bar was depressed with the right hand. Following a variable delay of 5-7 s (uniformly distributed), a single cylinder was illuminated. Subjects responded by reaching out and grasping it with their thumb and index finger, before lifting it out of its pedestal. On most trials, the cued cylinder remained illuminated throughout the entire response (stay). On some trials (40\%), however, the cued cylinder was switched once the touch-bar was released. This switch forced subjects to update their grasp aperture to accommodate the new target cylinder (switch).

A majority of trials were accompanied by either spTMS to left M1, or ppTMS to right PMv followed by left M1 8 ms later. In both cases, the test-pulse was applied at 75 or $100 \mathrm{~ms}$ after the initial cylinder illumination (CI $+75 \mathrm{~ms}$ or $\mathrm{CI}+100 \mathrm{~ms}$; premovement condition), or following movement onset $(\mathrm{MO}+75 \mathrm{~ms}$ or $\mathrm{MO}+100 \mathrm{~ms}$; perimovement condition). An inter-hemispheric ppTMS configuration was used because it was unclear whether both TMS coils could be reliably positioned over $\mathrm{PMv}$ and M1 within a single hemisphere in all subjects. A total of 160 trials were performed with spTMS, ppTMS, and no-TMS trials pseudorandomly interleaved within the same session. Subjects received spTMS on 60 trials, ppTMS on 60 trials, and no-TMS on 40 trials. The $8 \mathrm{~ms}$ conditioning-test pulse interval, $75 \mathrm{~ms}$ and $100 \mathrm{~ms}$ visual cue-to-TMS test-pulse latencies, and inter-hemispheric application of ppTMS have been shown to be appropriate in previous studies of premotor-M1 interactions (Koch et al., 2006; O'Shea et al., 2007; Davare et al., 2008).

TMS and electromyography recordings. TMS was applied using two Magstim200 (The Magstim Company) magnetic stimulators. A $50 \mathrm{~mm}$ figure-of-eight coil applied conditioning pulses over right PMv, and a 70 $\mathrm{mm}$ figure-of-eight coil applied test-pulses over left M1. The M1 "hotspot" was identified as the scalp location where stimulation reliably evoked the largest MEP amplitude in the FDI muscle of the right hand, with the intensity set to produce single-pulse MEPs of $\sim 1 \mathrm{mV}$ at rest. The PMv coil location was determined using an MRI-aligned frameless stereotaxic neuronavigation system (Brainsight, Rogue Research), and adjusted with respect to individual sulcal landmarks to be immediately posterior to the inferior precentral sulcus. The mean Montreal Neurological Institute (MNI) location across the subject group was 55.4, 14.7, 29.5 , which lies centrally within the region previously defined as PMv in the human brain (Mayka et al., 2006) and just posterior to the precentral operculum (Germann et al., 2005). PMv TMS was set at $110 \%$ of the resting motor threshold (RMT) for that hemisphere [suprathreshold conditioning pulses were used as in other inter-hemispheric ppTMS experiments (Koch et al., 2006; O’Shea et al., 2007; Mars et al., 2009)], defined as the intensity at which a small MEP $(\sim 50 \mu \mathrm{V}$ peak-to-peak amplitude) was evoked by stimulating M1 on 5 of 10 consecutive trials (Rossini et al., 1994). TMS coils were positioned tangential to the skull at the stimulation site, with the M1 coil angled at $\sim 45^{\circ}$ (handle pointing posteriorly), and the $\mathrm{PMv}$ coil angled at $90^{\circ}$ relative to the midline (handle pointing anteriorly) (Fig. 1). Coil positions were fixed in place by adjustable metal arms and monitored throughout the experiment.

Electromyography (EMG) was recorded from the first dorsal interosseus (FDI) and abductor pollicis brevis (APB) muscles of the right hand using a bipolar surface $\mathrm{Ag}$ - $\mathrm{AgCl}$ electrode montage. Responses were bandpass filtered between 10 and $1000 \mathrm{~Hz}$, with an additional $50 \mathrm{~Hz}$ notch filter, sampled at $5000 \mathrm{~Hz}$, and recorded using a CED 1902 amplifier, a CED micro $1401 \mathrm{Mk}$.II A/D converter, and a PC running Spike2 (Cambridge Electronic Design).

Analysis of electrophysiological data was based on peak-to-peak amplitudes of the MEPs measured on TMS trials. Trials in which the test pulse failed to elicit a reliable MEP were discarded from the analysis. MEP data from trials where all task parameters, except for cylinder size, were 
identical were combined and analyzed together. Because TMS coil placement and stimulator intensity were optimized for the FDI, we focus on these data.

A control experiment examined whether PPEs of PMv-M1 ppTMS were specific to that region or whether similar PPEs were found when both conditioning and test pulses were applied over left M1 using identical stimulation parameters.

Kinematic recordings. A Fastrack (Polhemus) motion analysis system was used to record Cartesian position data from three transmitters, which were attached to the finger nails of the right thumb and index finger, and adjacent to the ulnar styloid process of the right wrist. The system samples sequentially from the available transmitters at $120 \mathrm{~Hz}$, so that data for each individual transmitter was actually obtained at $40 \mathrm{~Hz}$. Kinematic recording was initiated 500 ms before cylinder illumination, and raw Cartesian data were stored for offline analysis performed with custom MATLAB (The MathWorks) software.

The time-series for each channel were corrected for TMS-related artifacts, and aligned in time via cubic spline interpolation, with the aligned data upsampled to $120 \mathrm{~Hz}$ for each channel. The grasp aperture timeseries was then computed as the Euclidean distance between the thumb and index finger position at each time-point. Event code markers associated with the EMG data were then used to align the grasping aperture and EMG data in time. The movement onset and offset were determined for each trial. To determine movement onset, the tangential displacement time-series with respect to the initial position was calculated for the wrist channel, and from this, the velocity profile was determined by computing the first derivative with respect to time and smoothing using a 200-ms-wide Gaussian (full-width at half-maximum $=0.94$ ) kernel. The onset was defined as the first point before the observed maximum velocity, in which the velocity exceeded $0.05 \mathrm{~cm} / \mathrm{s}$. The movement offset was marked by an event code recorded when the illuminated cylinder was touched.

The grasp aperture from movement onset to offset was then timenormalized by resampling via spline interpolation. The resulting series was made up of 100 time-points representing the percentage of the movement completed. For trials in which TMS was delivered, the timenormalized location of the TMS test-pulse was determined as well. Individual subject data were then averaged across trials for each type of kinematic $\times$ TMS condition, and pooled across the group. 95\% confidence intervals for the group mean were then computed using a bootstrap technique, repeated 10,000 times.

Diffusion-weighted MRI. We acquired diffusion-weighted (3 acquisitions of 60 directions, b-value $1000 \mathrm{~s} \times \mathrm{mm}^{-2}, 2 \times 2 \times 2 \mathrm{~mm}^{3}$ voxels, 72 slices) and T1-weighted data using a 1.5T Siemens Sonata MR scanner (Tomassini et al., 2007). The FMRIB Software Library (FSL; http://www. fmrib.ox.ac.uk/fsl) was used to analyze these data. Fractional anisotropy (FA) was computed with the FMRIB Diffusion Toolbox (FDT). All subjects' FA data were then coregistered to the FMRIB58_FA template in MNI152 standard space, using the FNIRT nonlinear registration tool. A mean FA image was created and then skeletonized using an FA threshold of 0.2. Voxelwise statistical analysis of the FA data was then performed using Tract-Based Spatial Statistics (TBSS) (Smith et al., 2006) from. With TBSS, each subject's aligned FA image was projected onto the mean skeleton by searching perpendicular from the skeleton for maximum FA values. This step allows for the statistical comparison of FA values from homologous regions of the FA map. Between-subject variance in FA from these homologous regions were then related to between-subject variance in observed physiological (stay - switch PPE contrast at MO $+75 \mathrm{~ms}$ and $\mathrm{MO}+100 \mathrm{~ms}$ ) and behavioral (grasp aperture distance between large cylinder stay and small-to-large cylinder switch trials measured at $50 \%$ of MT for ppTMS applied at MO $+75 \mathrm{~ms}$ ) effects, by using each as a GLM regressor in TBSS (Boorman et al., 2007). The resulting voxelwise statistical images were thresholded at $p \leq 0.005$. Individual clusters consisting of 15 or more voxels were then masked, and the average FA within the cluster was determined for each subject. The average FA values were then correlated with the MEP effect-size to determine the correlation coefficient for the cluster.
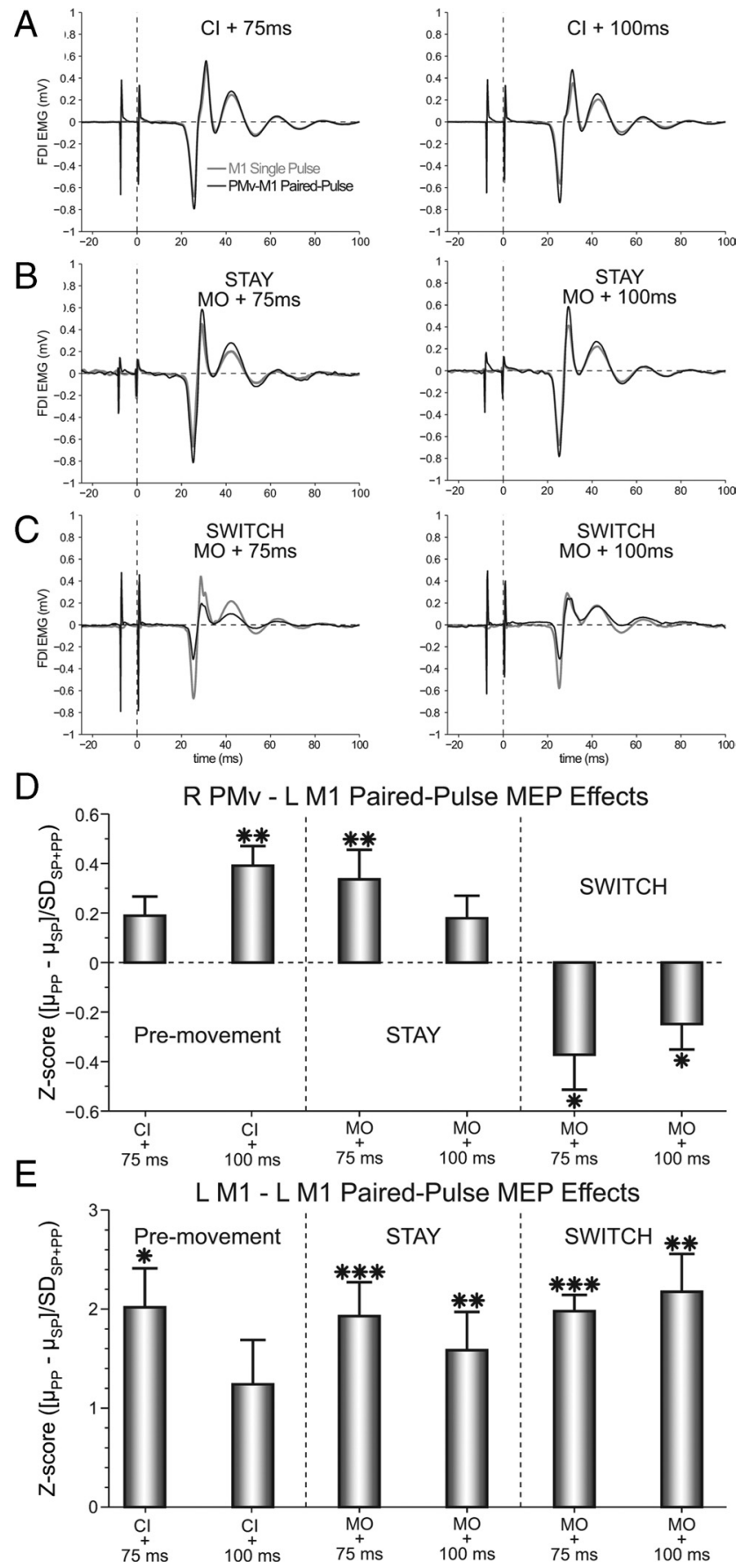

Figure 2. PMv-M1 ppTMS facilitated M1 corticospinal activity during the premovement period and in the perimovement stay condition. However, the PPE switched to perimovement inhibition when the action had to be inhibited and reprogrammed on switch trials. $A-C$, Example FDI MEPs recorded after M1 spTMS and PMv-M1 ppTMS during $(\boldsymbol{A})$ premovement, and perimovement $(\boldsymbol{B})$ stay and $(\boldsymbol{C})$ switch conditions. $\boldsymbol{D}$, Group mean PPEs for each condition in the FDI muscle. $\boldsymbol{E}$, A nonspecific facilitatory PPE was observed across all conditions when M1-M1 ppTMS was applied. Error bars represent SEM. ${ }^{*} p<0.05,{ }^{* *} p<0.01,{ }^{* * *} p<0.001$.

\section{Results}

\section{Physiological effects of PMv-M1 ppTMS}

Task-related PMv-M1 PPEs were indexed by Z-scores computed as the difference of the mean ppTMS minus spTMS MEP magnitudes divided by the pooled standard deviation. Thus, the reported PPEs are relative to the observed within-subject variance for each condition (Fig. 2; for an alternative analysis approach, 
see supplemental information, available at www.jneurosci.org as supplemental material). During the premovement period, a two-way ANOVA [Muscle (APB vs FDI $) \times$ Time $(\mathrm{CI}+75$ vs $\mathrm{CI}+100 \mathrm{~ms})]$ revealed a significant Muscle $\times$ Time interaction $\left(F_{(1,13)}=5.02 ; p<0.05\right)$. Onesample $t$ tests confirmed a significant facilitatory PPE for the FDI at CI $+100 \mathrm{~ms}$ $\left(t_{(13)}=3.04\right.$; $\left.p<0.01\right)$. During the perimovement period, a three-way ANOVA [Muscle $(\mathrm{APB}$ vs FDI) $\times$ Context (switch vs stay) $\times$ Time $(\mathrm{MO}+75 \mathrm{~ms}$ vs $\mathrm{MO}$ $+100 \mathrm{~ms})$ ] showed a significant main effect of Context $\left(F_{(1,13)}=5.66 ; p<0.05\right)$, a Muscle $\times$ Time interaction $\left(F_{(1,13)}=\right.$ 15.60; $p<0.01)$, and a Context $\times$ Time interaction $\left(F_{(1,13)}=5.17 ; p<0.05\right)$. Again, subsequent one-sample $t$ tests revealed a significant facilitatory PPE for the FDI at $\mathrm{MO}+75 \mathrm{~ms}$ during stay trials $\left(t_{(13)}\right.$ $=2.86 ; p<0.01$ ). Alternatively, during switch trials this PPE became inhibitory, which was significant at both $\mathrm{MO}+75 \mathrm{~ms}$ $\left(t_{(13)}=-2.45 ; p<0.05\right)$ and $\mathrm{MO}+100$ $\mathrm{ms}\left(t_{(13)}=-2.184 ; p<0.05\right)$. Cylinder size was not associated with any differences in these effects.

A similar pattern of PMv-M1 PPEs were observed in MEPs recorded from the APB muscle (supplemental Fig. 1, available at www.jneurosci.org as supplemental material) during the premovement period. As in the FDI muscle, one-sample $t$ tests confirmed a significant facilitatory PPE for the APB at CI $+100 \mathrm{~ms}\left(t_{(13)}=2.388 ; p<0.05\right)$. Differences between the two muscles were observed during the perimovement period, however. Here, one-sample $t$ tests for the APB muscle did not show a significant ppTMS facilitation of MEPs during stay trials (both $t_{(13)} \leq 1.903$; both $p \geq 0.079$ ). During switch trials, the APB did show a significant inhibition at $\mathrm{MO}+75 \mathrm{~ms}\left(t_{(13)}=-3.49 ; p<0.01\right)$, similar to the effect observed in FDI. Thus, some of the significant facilitation and inhibition effects observed for FDI, also appeared to be present for $\mathrm{APB}$, while others were absent. Although these observations might represent differential involvement of FDI and APB at specific points of the task, the design of this study does not assess this question. The primary reason for this is that the selected stimulation parameters (including the location of left M1 stimulation, and right PMv and left M1 stimulation intensities) were optimized based only on the FDI response. Thus, nonoptimal stimulation parameters for the APB muscle cannot be ruled out as a source of these differences.

\section{Behavioral effects of PMv stimulation}

Since the direction (facilitation or inhibition) of significant PPEs for PMv-M1 ppTMS was related to the task context (stay or switch) at $\mathrm{MO}+75 \mathrm{~ms}$, the analysis of related kinematic effects also focused on trials at this time-point. It has previously been shown that action reprogramming is particularly vulnerable to disruptive TMS applied to the parietal cortex shortly after the cylinder switch occurs on small-to-large switch trials (Glover et al., 2005). Therefore, it was expected that PMv-M1 ppTMS might also particularly disrupt grasping reprogramming on small-to-large cylinder switch trials.
Large Cylinder Stay and Small-to-Large Cylinder Switch Trials
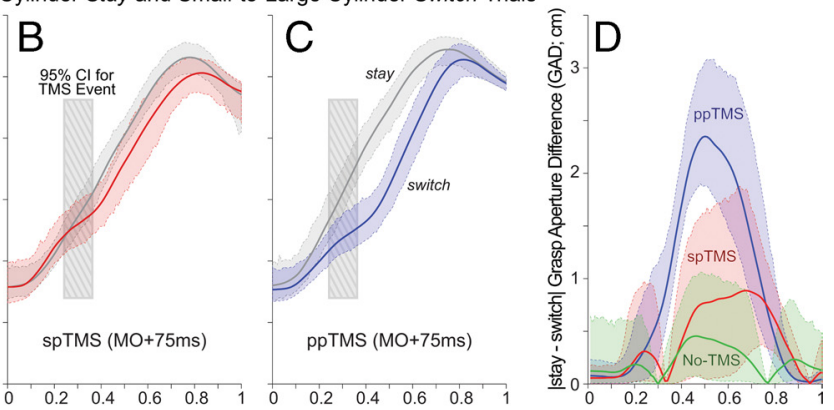

Small Cylinder Stay and Large-to-Small Cylinder Switch Trials

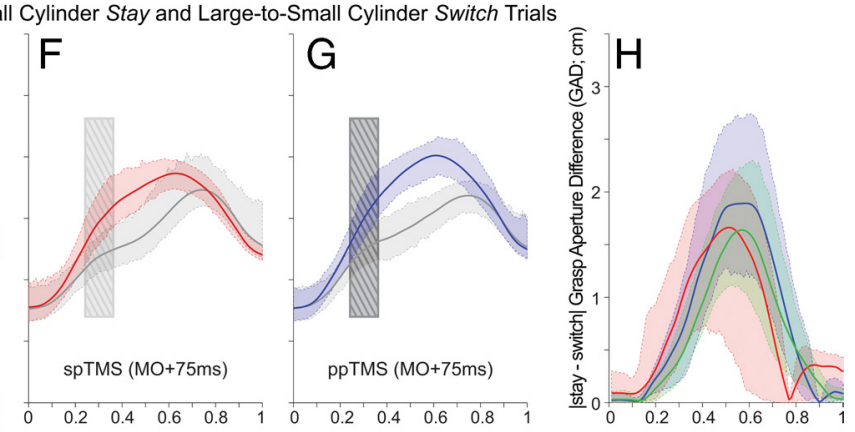

Figure 3. $\quad \boldsymbol{A}-\boldsymbol{D}, \mathrm{PMv}-\mathrm{M} 1 \mathrm{ppTMS}$ led to slower reprogramming on small-to-large cylinder switch trials $(\boldsymbol{A})$, relative to the spTMS throughout the movement, with dashed lines representing the $95 \% \mathrm{Cl}$ of the mean. The hatched box represents the $95 \% \mathrm{Cl}$ of the mean occurrence of TMS stimulation following time normalization.

Indeed, the application of PMv-M1 ppTMS at MO $+75 \mathrm{~ms}$ caused a specific delay in grasp aperture adjustments on smallto-large cylinder switch trials, relative to no-TMS or spTMS applied at this time (Fig. $3 A-C$ ). This was quantitatively assessed by comparing the grasp aperture difference (GAD) between large cylinder stay and small-to-large cylinder switch trials (Fig. 3D) at three points throughout the movement. A two-factor ANOVA [TMS (no-TMS vs spTMS vs ppTMS) $\times$ Normalized Time $(25 \%$ vs $50 \%$ vs $75 \%)$ ] revealed significant main effects for TMS $\left(F_{(1.70,22.14)}=11.70 ; p<0.001\right)$, and Normalized Time $\left(F_{(2,26)}=\right.$ $10.06 ; p<0.001)$. The TMS $\times$ Normalized Time $\left(F_{(3.90,50.67)}=\right.$ $4.51 ; p<0.01)$ interaction was significant as well. Paired-sample $t$ tests showed a significantly greater GAD for ppTMS trials at the $50 \%$ time-point than for the no-TMS $\left(t_{(13)}=-6.99 ; p<0.001\right)$ or $\operatorname{spTMS}\left(t_{(13)}=-3.20 ; p<0.01\right)$ conditions. There were no significant differences observed between the no-TMS and spTMS conditions $\left(t_{(13)}=-1.05 ; p=0.31\right)$ at this time-point, and none observed between TMS conditions at the other two ( $25 \%$ or $75 \%)$.

\section{Anatomical connections associated with physiological and behavioral effects of PMv-M1 ppTMS}

A number of white-matter regions were found in which FA correlated with between-subject differences in the stay - switch PPE contrast at $\mathrm{MO}+75 \mathrm{~ms}$ and $\mathrm{MO}+100 \mathrm{~ms}$ (supplemental Table 1, available at www.jneurosci.org as supplemental material), with the largest clusters emerging in the vicinity of PFv and IPS in the right hemisphere. Overlapping clusters were found in the right $\mathrm{PFv}$ adjacent to the inferior frontal sulcus and the frontal operculum (Fig. $4 A$ ) at both $\mathrm{MO}+75 \mathrm{~ms}$ and $\mathrm{MO}+100 \mathrm{~ms}$. The largest region of correlation, near the right IPS (Fig. 4C), only emerged at the later $\mathrm{MO}+100 \mathrm{~ms}$ time period (Fig. 4C) as did a smaller region of correlation near right $\mathrm{PMv}$ (Fig. $4 B$ ). In relation to 
Stay - Switch MEP Contrast (Z-score) vs. Fractional Anisotropy (FA)
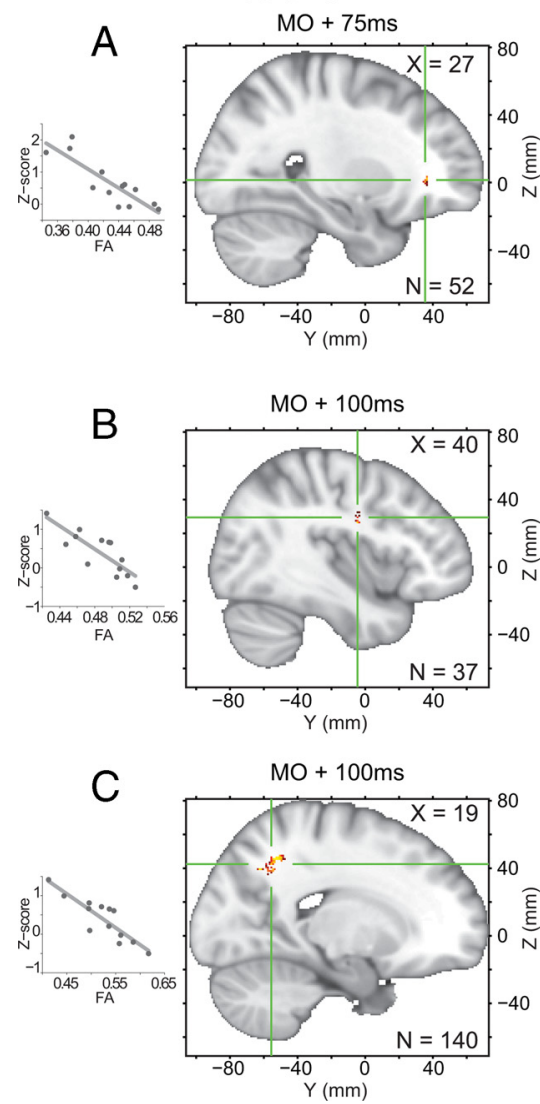

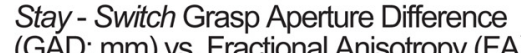
(GAD; mm) vs. Fractional Anisotropy (FA)
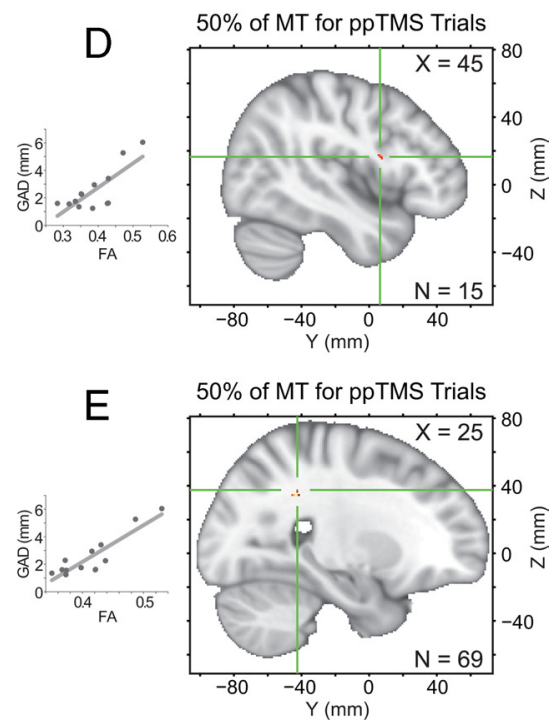

Figure 4. $\boldsymbol{A}-\boldsymbol{E}$, White-matter $\mathrm{FA}$ relationships with physiological $(\boldsymbol{A}-\boldsymbol{C})$ and behavioral $(\boldsymbol{D}-\boldsymbol{E})$ effects produced by $\mathrm{PMv}-\mathrm{M} 1$ ppTMS. Clusters highlighting regions that showed differential PPEs relative to the behavioral context (stay vs switch) emerged in (A) PFv at M0 $+75 \mathrm{~ms}$, and (B) PMv and (C) IPS at MO + $100 \mathrm{~ms}$. Similar (D) PMv and (E) IPS clusters emerge when FA is regressed against GAD measured at $50 \%$ of MT ( $\sim 300-400$ ms after the MO +100 ms time-point). Correlation clusters are indicated by red-yellow colored voxels, with green cross-hairs through the center-of-mass. Inset scatter-plots depict the FA and regressor relationships for each cluster.

behavioral effects, adjacent right PMv (Fig. 4D) and IPS (Fig. 4E) clusters showed a significant correlation between FA and GAD measured at $50 \%$ of MT $(\sim 300-400 \mathrm{~ms}$ after the MO $+100 \mathrm{~ms}$ time-point).

\section{Control experiment and analyses}

A control experiment confirmed that the differential, contextbased PMv-M1 PPEs were specific to that interaction and could not be explained by simple superposition of the conditioning and test pulses over left M1. When both the conditioning pulse and test pulse were applied through the same coil over left M1, the same three-way ANOVA [Muscle $(\mathrm{APB}$ vs FDI $) \times$ Context ( switch vs stay) $\times$ Time $(\mathrm{MO}+75 \mathrm{~ms}$ vs $\mathrm{MO}+100 \mathrm{~ms})]$ used to compare perimovement conditions in the main experiment revealed no significant main (all $F_{(1,5)} \leq 1.304$; all $p \geq 0.305$ ) or interaction effects (all $F_{(1,5)} \leq 3.829$; all $p \geq 0.108$ ). As the conditioning pulse over left M1 appeared to exert a facilitatory effect on test pulse for all conditions in both muscles, a three-way ANOVA [TMS (single vs paired-pulse) $\times$ Context (switch vs stay) $\times$ Time $(\mathrm{MO}+75 \mathrm{~ms}$ vs $\mathrm{MO}+100 \mathrm{~ms})]$ was performed on the raw data in each muscle to assess this statistically. As expected, both the FDI $\left(F_{(1,5)}=21.967 ; p<0.01\right)$ and $\operatorname{APB}\left(F_{(1,5)}\right.$ $=21.696 ; p<0.01)$ muscles showed only a significant main effect for TMS.
Furthermore, data from the main experiment suggest that the change from facilitation to inhibition cannot be attributed to a change in excitability in the M1 region during action reprogramming. A two-way ANOVA [Context (stay vs switch $) \times$ Time $(\mathrm{MO}+75$ vs $\mathrm{MO}+100$ $\mathrm{ms}$ )] assessing differences in MEP magnitude during trials in which single pulses were applied over M1, revealed no significant main (Context: $F_{(1,13)}=0.206 ; p=$ 0.657; Time: $\left.F_{(1,13)}=1.704 ; p=0.214\right)$ or interaction $\left(F_{(1,13)}=0.002 ; p=0.966\right)$ effects.

Another potential confound, particularly when measuring MEPs during movement, could be related to systematic differences in background EMG activity between conditions at the time when TMS was applied. To address this, a three-way ANOVA [TMS (single pulse vs pairedpulse $) \times$ Context (stay vs switch) $\times$ Time $(\mathrm{MO}+75 \mathrm{~ms}$ vs $\mathrm{MO}+100 \mathrm{~ms})]$ was conducted for the root mean square (RMS) of the background EMG in a $100 \mathrm{~ms}$ window ending $10 \mathrm{~ms}$ before the application of the TMS test pulse (so that the conditioning pulse artifact was not included for pairedpulse trials). No significant main (all $F_{(1,13)} \leq 2.571$; all $\left.p \geq 0.133\right)$ or interaction (all $F_{(1,13)} \leq 2.985$; all $p \geq 0.108$ ) effects were found for this comparison. Therefore, MEP amplitude effects were not confounded with differences in FDI muscle contraction states.

Finally, reaction (RT) and movement time (MT) were calculated and statistically compared for perimovement conditions (supplemental Fig. 2, available at www.jneurosci.org as supplemental material). Three-way ANOVAs [TMS (single vs paired-pulse) $\times$ Context (switch vs stay) $\times$ Time $(\mathrm{MO}+75 \mathrm{~ms}$ vs $\mathrm{MO}+100 \mathrm{~ms})$ ] were performed on both measures. For RT, the results of the ANOVA showed no significant main or interaction effects ( $p \geq 0.185)$. For MT, there was a significant main effect for Time $(p<0.05)$, while no other effects were significant $(p \geq 0.179)$.

\section{Discussion}

The combination of three methods, ppTMS, kinematic recordings, and DW-MRI, provides a detailed picture of functional interactions that occur during action reprogramming. First, it was shown that physiological interactions between PMv and M1 change with behavioral context. While PMv facilitated M1 activity during the preparation and execution of a normal movement, it inhibited M1 activity when the initial action had to be suppressed and a new one selected. Furthermore, with ppTMS it was possible to probe functional interactions at a high temporal resolution and to show that this change in the PPE happened within $75 \mathrm{~ms}$ of the change in task context.

Previous studies have reported task-related facilitation of M1 corticospinal activity by PMd (Koch et al., 2006; O'Shea et al., 2007), PMv (Davare et al., 2008), and pre-SMA (Mars et al., 2009). Although there has been evidence for a change to an in- 
hibitory influence when inter-pulse-interval or stimulation intensity are varied, these differential effects have not always been clear during motor task performance. In contrast, the present study showed that a change in behavioral context is sufficient to cause a complete reversal of the influence exerted by PMv over M1 (within the same subject and test session), even in the absence of a change in stimulation parameters. The change from facilitation to inhibition cannot be explained by a change in local excitability within left M1, as spTMS applied over M1 on both switch and stay trials elicited similar sized MEPs. Similarly, paired microwire stimulation of PMv and M1 in macaques has also been shown to exert both facilitatory and inhibitory effects on MEPs during grasping movements (Prabhu et al., 2009). In humans, the muscle-specific nature of these PPEs appears to depend on the functional role of each muscle during the particular grasping movement being made (Davare et al., 2008). Here, similar patterns of PPEs emerged regardless of whether subjects were switching to or from the large or small cylinder. As a similar precision grasp was used for all trials, the FDI played a relatively constant functional role throughout the experiment.

Activity in inferior frontal cortex (extending into PMv) increases when people inhibit actions, and lesions or disruptive TMS applied to this region impair the ability to withhold movements (Aron et al., 2004; Forstmann et al., 2008). Although it has been suggested that PMv exerts an inhibitory physiological influence over other brain areas, including M1 (Aron et al., 2004), the degree to which inhibition of action at a behavioral level can be related to inhibition at a physiological level has been difficult to ascertain. The present findings demonstrate that PMv does indeed exert an inhibitory influence over M1 when an action has to be inhibited and reprogrammed. Moreover, the short latency of the inhibitory influence, just $8 \mathrm{~ms}$ elapsed between the PMv and M1 pulses, suggests that it occurs in a relatively direct manner that need not depend on a multisynaptic route via the basal ganglia, as has been speculated.

An attempt was also made to assess the impact this inhibitory physiological effect had on behavior. Although the applied stimulation was not optimized to disrupt performance, it still caused a reduction in grasp aperture adjustments measured at the midpoint of the movement on switch trials. In PMv, unlike M1, populations of neurons encode different grasping movements not just before movement but throughout the course of movement (Umilta et al., 2007). One interpretation of the PMv switch effect is that, under circumstances where reprogramming is required, $\mathrm{PMv}$ generates a specific pattern of inhibition across M1 that leads to decreased activity in M1 corticospinal neurons associated with the initial movement. This selective inhibition beneficially minimizes the inertial consequences of the initial action on any alternative movement being made. When TMS is applied to PMv in the same context, the TMS pulse augments the inhibitory influence of PMv but may induce a nonspecific pattern of inhibition over M1 that leads to temporary inhibition of all on-going movements. Although the behavioral impact of TMS depends on the direction of size change, similar patterns of neurophysiological change were seen regardless of cylinder size.

Consistent with the idea that PFv and opercular frontal regions influence PMv during reprogramming through the selection of task-relevant information, we observed that FA in a region adjacent to the inferior frontal sulcus was significantly correlated with between-subject differences in the size of the contextdependent influence of PMv on M1. Furthermore, overlapping $\mathrm{PFv}$ clusters emerged for the physiological regressor at both MO $+75 \mathrm{~ms}$ and $\mathrm{MO}+100 \mathrm{~ms}$, but none emerged for the kinematic regressor which was measured $\sim 300-400 \mathrm{~ms}$ following the MO +100 ms time-point. In contrast, similar PMv and IPS clusters only showed significant correlations with the physiological regressor at $\mathrm{MO}+100 \mathrm{~ms}$, and the kinematic regressor. This suggests that PFv plays an early role in influencing PMv during reprogramming and that, as the action evolves, PMv and IPS emerge as major influences over M1.

One caveat related to the interpretation of these data is that if actions are represented in a hierarchical framework (Rosenbaum et al., 2007; Majdandzic et al., 2009), then one might argue that the action reprogramming required by this task was related to the kinematics of the action rather than a complete change in every aspect of the intended final goal state. Given the importance of $\mathrm{PMv}$ in representing the kinematics of grasping movements (Majdandzic et al., 2009), it is unclear whether similar effects would be seen if other aspects of the action had been reprogrammed instead. An important point is that while the influence of PMv during action reprogramming may depend on input from $\mathrm{PFv}$, this is only one part of an extended circuit of brain regions that influence action reprogramming. The size of the contextdependent inhibitory influence of PMv was also correlated with other prominent regions of FA. The sagittal stratum, adjacent to the IPS, is the bundle mediating connections to the pons and cerebellum. Smaller regions of FA near premotor cortex itself were found, as well. All of these regions have been implicated in on-line updating of hand position and movement trajectories (Desmurget et al., 1999; Rushworth et al., 2001; Glover et al., 2005; Tunik et al., 2005; Lee and van Donkelaar, 2006).

Even if PMv does mediate action inhibition, it is clear that its influence is not confined to such a role. In fact, a second novel finding was that PMv exerted a protracted excitatory influence over M1 corticospinal activity even when reprogramming was not required. ppTMS investigations of PMd and pre-SMA have suggested that these regions exert their major influence over M1 in a transitory manner between 75 and $125 \mathrm{~ms}$ after the presentation of the cue instructing movement (Koch et al., 2006, O'Shea et al., 2007, Mars et al., 2009). In contrast, little has been known of how PMv-M1 interactions evolve during the course of an action. PMv stimulation facilitated M1 activity at the end of the movement preparation period, as well as after movement onset occurred. Such a protracted influence is consistent with $\mathrm{PMv}$ facilitation of M1 even when subjects maintain static hand postures (Davare et al., 2008), and with demonstrations that other areas in the PMv network influence movement even when the need for updating is not explicitly manipulated (Tunik et al., 2008).

In conclusion, PMv exerts a protracted influence over M1that can rapidly change between facilitation and inhibition depending on behavioral context. Inhibition of M1 corticospinal activity is mediated by an interconnected network of areas spanning prefrontal, premotor, and parietal cortex when actions are inhibited and reprogrammed.

\section{References}

Aron AR, Robbins TW, Poldrack RA (2004) Inhibition and the right inferior frontal cortex. Trends Cogn Sci 8:170-177.

Boorman ED, O'Shea J, Sebastian C, Rushworth MF, Johansen-Berg H (2007) Individual differences in white-matter microstructure reflect variation in functional connectivity during choice. Curr Biol 17:1426-1431.

Davare M, Lemon R, Olivier E (2008) Selective modulation of interactions between ventral premotor cortex and primary motor cortex during precision grasping in humans. J Physiol 586:2735-2742.

Desmurget M, Epstein CM, Turner RS, Prablanc C, Alexander GE, Grafton 
ST (1999) Role of the posterior parietal cortex in updating reachiing movements to a visual target. Nat Neurosci 2:563-567.

Dum RP, Strick PL (2005) Frontal lobe inputs to the digit representations of the motor areas on the lateral surface of the hemisphere. J Neurosci 25:1375-1386.

Everling S, Tinsley CJ, Gaffan D, Duncan J (2002) Filtering of neural signals by focused attention in the monkey prefrontal cortex. Nat Neurosci 5:671-676.

Forstmann BU, Jahfari S, Scholte HS, Wolfensteller U, van den Wildenberg WP, Ridderinkhof KR (2008) Function and structure of the right inferior frontal cortex predict individual differences in response inhibition: a model-based approach. J Neurosci 28:9790-9796.

Germann J, Robbins S, Halsband U, Petrides M (2005) Precentral sulcal complex of the human brain: morphology and statistical probability maps. J Comp Neurol 493:334-356.

Glover S, Miall RC, Rushworth MF (2005) Parietal rTMS disrupts the initiation but not the execution of on-line adjustments to a perturbation of object size. J Cogn Neurosci 17:124-136.

Godschalk M, Lemon RN, Kuypers HG, Ronday HK (1984) Cortical afferents and efferents of monkey postarcuate area: an anatomical and electrophysiological study. Exp Brain Res 56:410-424.

Koch G, Franca M, Del Olmo MF, Cheeran B, Milton R, Alvarez Sauco M, Rothwell JC (2006) Time course of functional connectivity between dorsal premotor and contralateral motor cortex during movement selection. J Neurosci 26:7452-7459.

Lee JH, van Donkelaar P (2006) The human dorsal premotor cortex generates on-line error corrections during sensorimotor adaptation. J Neurosci 26:3330-3334.

Majdandzic J, Bekkering H, van Schie HT, Toni I (2009) Movement-specific repetition suppression in ventral and dorsal premotor cortex during action observation. Cereb Cortex 19:2736-2745.

Mars RB, Klein MC, Neubert FX, Olivier E, Buch ER, Boorman ED, Rushworth MF (2009) Short-latency influence of medial frontal cortex on primary motor cortex during action selection under conflict. J Neurosci 29:6926-6931.

Mayka MA, Corcos DM, Leurgans SE, Vaillancourt DE (2006) Threedimensional locations and boundaries of motor and premotor cortices as defined by functional brain imaging: a meta-analysis. Neuroimage 31:1453-1474.

O'Shea J, Sebastian C, Boorman ED, Johansen-Berg H, Rushworth MF (2007) Functional specificity of human premotor-motor cortical interactions during action selection. Eur J Neurosci 26:2085-2095.

Prabhu G, Shimazu H, Cerri G, Brochier T, Spinks RL, Maier MA, Lemon RN
(2009) Modulation of primary motor cortex outputs from ventral premotor cortex during visually guided grasp in the macaque monkey. J Physiol 587:1057-1069.

Rosenbaum DA, Cohen RG, Jax SA, Weiss DJ, van der Wel R (2007) The problem of serial order in behavior: Lashley's legacy. Hum Mov Sci 26:525-554.

Rossini PM, Barker AT, Berardelli A, Caramia MD, Caruso G, Cracco RQ, Dimitrijević MR, Hallett M, Katayama Y, Lücking $\mathrm{CH}$, Maertens de Noordhout AL, Marsden CD, Murray NM, Rothwell JC, Swash M, Tomberg C (1994) Non-invasive electrical and magnetic stimulation. Electroencephalogr Clin Neurophysiol 91:79-92.

Rushworth MF, Ellison A, Walsh V (2001) Complementary localization and lateralization of orienting and motor attention. Nat Neurosci 4:656-661.

Rushworth MF, Buckley MJ, Gough PM, Alexander IH, Kyriazis D, McDonald KR, Passingham RE (2005) Attentional selection and action selection in the ventral and orbital prefrontal cortex. J Neurosci 25:11628-11636.

Rushworth MF, Behrens TE, Johansen-Berg H (2006) Connection patterns distinguish 3 regions of human parietal cortex. Cereb Cortex 16:1418-1430.

Shimazu H, Maier MA, Cerri G, Kirkwood PA, Lemon RN (2004) Macaque ventral premotor cortex exerts powerful facilitation of motor cortex outputs to upper limb motoneurons. J Neurosci 24:1200-1211.

Smith SM, Jenkinson M, Johansen-Berg H, Rueckert D, Nichols TE, Mackay CE, Watkins KE, Ciccarelli O, Cader MZ, Matthews PM, Behrens TE (2006) Tract-based spatial statistics: voxelwise analysis of multi-subject diffusion data. Neuroimage 31:1487-1505.

Tomassini V, Jbabdi S, Klein JC, Behrens TE, Pozzilli C, Matthews PM, Rushworth MF, Johansen-Berg H (2007) Diffusion-weighted imaging tractography-based parcellation of the human lateral premotor cortex identifies dorsal and ventral subregions with anatomical and functional specializations. J Neurosci 27:10259-10269.

Tunik E, Frey SH, Grafton ST (2005) Virtual lesions of the anterior intraparietal area disrupt goal-dependent on-line adjustments of grasp. Nat Neurosci 8:505-511.

Tunik E, Lo OY, Adamovich SV (2008) Transcranial magnetic stimulation to the frontal operculum and supramarginal gyrus disrupts planning of outcome-based hand-object interactions. J Neurosci 28:14422-14427.

Umilta MA, Brochier T, Spinks RL, Lemon RN (2007) Simultaneous recording of macaque premotor and primary motor cortex neuronal populations reveals different functional contributions to visuomotor grasp. J Neurophysiol 98:488-501.

Verhagen L, Dijkerman HC, Grol MJ, Toni I (2008) Perceptuo-motor interactions during prehension movements. J Neurosci 28:4726-4735. 